\title{
IS GREEN A SUPER DEAL? GREEN ENERGY AND ITS REAL COST AND BENEFIT FOR CUSTOMERS
}

\author{
Klára HORNÁ \\ Mendel University in Brno, Faculty of Business and Economics
}

\begin{abstract}
Nowadays, the phenomenon of sustainability in a form of green energy is one of the most discussed topics in public as well as in government, especially in the European Union. A change of lifestyle, new trends in the industry, expanding e-mobility; all these factors increase the demand of electricity. On the other side of the equation is supply, which is highly influenced by the government decisions. New trend in Europe is to decrease amount of coal and nuclear power plants which are considered to be non-ecological, together with stimulation of growth in matter of renewable resources. The paper analyses one of the stimulation tools - the market of Renewable Energy Guarantees of Origin. The purpose of this analysis is to compare real impact of the guarantees with their marketing impact. Electricity is a specific commodity which cannot be stored, and its origin cannot be identified. Because of these specifics the market of Renewable Energy Guarantees of Origin exists along with the energy market. The number of guarantees depends on the total amount of MWh produced without further identification of the units sold. The initial price is given by the regulator of the market and the final price is given by the market. It must be noted, that in Europe there is one market with regional submarkets whose quality is guaranteed by the Association of Issuing Bodies IVZW (AIB) registered in Brussels, Belgium, and so international trade is possible.

Purpose: The paper analyses the framework given by law and regulators, the mechanics of both energy market and energy guarantees market. The outcome is compared with the marketing strategy of sales companies. The purpose of this analysis is to compare real impact of the guarantees with their marketing impact.

Methodology: Empirical analysis of the markets and their structures, questionaire. Findings: Conclusion following the analysis is that the trade model of Renewable Energy Guarantees of Origin has negligible impact as growth stimulator of the industry. The guarantees are more likely to be only a marketing tool which could be considered a part of the greenwashing trend - so called green solution without real impact on the environmental aspects
\end{abstract}

Key words: energy market, green energy, marketing, Renewable Energy Guarantees of Origin, renewables

\section{Introduction}

Together with the renewables the green energy is 21 st century's phenomenon and one of the most discussed topics within sustainability. On one side we have supporters of new solutions, on the other side there is discussion whether the renewables will sufficiently cover consumption without causing fluctuations in network and if they are really green, considering the material used for their production, such as photovoltaics. Who is right? It is hard to tell because the answer is in the middle and this topic is not black or white.

The paper analyses one part of the puzzle - the green electricity and the market of Renewable Energy Guarantees of origin. The purpose of this analysis is to 
compare the real impact of the guarantees with their marketing impact. The aim is to answer the question whether green energy as a product is only a marketing tool or if it has a real added value on the amount of green electricity produced.

\section{Literature review / Research Background}

Electricity and its transmission to sustainability is described in many papers as emission decreasing is a huge part of environmental goals. Mostly there are discussion about the importance of supply chains for a low carbon, sustainable, and secure future with a focus on the links between water intensity, land use, GHG emissions, and materials supply, and energy generation (Arent, 2014). On the other hand, there is criticism of unproper costs, mistakes in processes and possible space for corruption as there is a pressure from interest groups (Morriss, 2011).

Also, the mechanisms of the trading and pricing is very important as liberalization of the markets is on different level in each country and the regulation policy can vary (McGowan, 1990).

One aspect of the renewables is the technical point of view and the framework of the market, but as long as it is area with impact on everyone, there is a need to examine end customers' perception and preferences, too. In this concern, there are also research available, with focus on behavioural economics and willingness to pay. One of them is the research done in Greece, in which different perception from individual's point of view and the interest of the community is examined (Kontogianni, Tourkolias, Skourtos, 2013). Another aspect is willingness to pay extra for green solutions (Goett, Hudson, Train, 2000).

The background of the research is based on papers focused on both - framework and behaviour of the customers using empirical methods, with consideration of legal framework of the market in Czech Republic. For preparation of the questionnaire about willingness to pay the previous research of customer behaviour were used.

\section{Methodology}

The paper analyses the framework given by law and regulators in Czech Republic and the mechanics of both energy market and energy guarantees market. The outcome is compared with the marketing strategy of the sales companies. For the purpose of the analysis so called biggest players on the Czech market, which are also obligatory buyers of green electricity, determined by $\S$ Law no. 165/2012 Sb. were chosen. These chosen companies are ČEZ Prodej, a.s., E.ON Energie, a.s. and Pražská energetika, a.s.

Moreover, to examine the impact of the certificates the customer research was done. The research was done by online questionnaire with simple questions about knowledge of green electricity and willingness to pay for it. 


\section{Results and discussion}

There are several circumstances why market of the renewables is developing as it is - increasing of production but at the same time decreasing of total share. The examination of all independent variables is not object of the paper and we focused only on the certificates.

Analysis showed that certificates have negligible impact as growth stimulator of the industry, because of the transaction cost, which causes dead weight loss and because of the fact, that demand and supply equilibrium is lower than production, based on energy mix of the chosen companies from table 1 and results of the customer research, where less than $5 \%$ from total amount of respondents would be interested in green electricity if price would be higher

. Table 1. National energy mix in 2019

\begin{tabular}{|l|l|l|l|l|l|l|l|}
\hline & 2013 & 2014 & 2015 & 2016 & 2017 & 2018 & 2019 \\
\hline Renewables & 5,68 & 10,95 & 11,7 & 10,11 & 7,6 & 6,17 & 3,9 \\
\hline Sun & 1,96 & 2,63 & 2,88 & 2,77 & 2,14 & 2,07 & 1,66 \\
\hline Wind & 0,47 & 0,57 & 0,71 & 0,63 & 0,45 & 0,22 & 0,00 \\
\hline Water & 1,93 & 2,56 & 2,67 & 1,15 & 1,43 & 0,77 & 0,44 \\
\hline Geothermal & 0,00 & 0,00 & 0,00 & 0,00 & 0,00 & 0,00 & 0,00 \\
\hline Biomass & 1,33 & 2,19 & 2,34 & 5,57 & 3,58 & 3,11 & 1,81 \\
\hline Others & 0,00 & 2,99 & 3,17 & 0,00 & 0,00 & 0,00 & 0,00 \\
\hline Fossil & 57,65 & 52,77 & 55,10 & 59,53 & 57,40 & 56,95 & 57,01 \\
\hline Nuclear & 36,67 & 36,28 & 33,13 & 30,36 & 35,01 & 36,88 & 39,09 \\
\hline
\end{tabular}

Source: OTE

\section{Energy market and market of renewable energy guarantees of origin}

The specific parameter of energy trade is, that it is impossible to store commodity. There are three options how the electricity can be traded:

- Over the Counter

- Broker platform

- Exchange

o Power Exchange Central Europe (PXE)

o European Energy Exchange (EEX)

The reason to set up the market of Renewable Energy Guarantees of Origin was that the identification of specific kind of electricity traded is technically impossible

. These so called 'certificates' are separately traded between supplier and manufacturer or supplier and supplier because the certificates are transferable and tradable within European Union.

The quality of the certificates and trade rules are guaranteed by the Association of Issuing Bodies IVZW (AIB) registered in Brussels, Belgium. Trade with guarantees started in 2013. Initial price is given by regulator of the market. Regional guarantees in Czech Republic are issued by OTE, a.s., which is state institution set 
up by law and it is responsible for operating of the market. The price for issuing a guarantee of origin is $1,25 \mathrm{CZK} / \mathrm{MWh}$, transaction fee $0,25 \mathrm{CZK} / \mathrm{MWh}$ and the price for maintaining an account in the register of guarantees of origin is $100 \mathrm{CZK} / \mathrm{monthly}$.

On one hand there are transaction costs, but on the other hand there are subsidies from the same institute in the form of given price. Given by $\S$ Law no. 165/2012 Sb. OTE pays to obligatory buyer the difference between purchase price and hourly price and the price for its activities. The final price is given by regulator and it is a form of direct subsidy.

Table 2. The price for the activity of the obligatory buyer

\begin{tabular}{|l|c|}
\hline & Price CZK/MWh \\
\hline ČEZ Prodej, a.s. & 203,53 \\
\hline E.ON Energie, a.s. & 192,19 \\
\hline Pražská energetika, a.s & 832,60 \\
\hline
\end{tabular}

Source: OTE

\section{Analysis of suppliers}

All three main suppliers run campaign about green electricity. The average price for 'green' tariffs was around $30 \mathrm{CZK} / \mathrm{MWh}$ extra, for example ČEZ offered regular tariff STANDARD for $1699 \mathrm{CZK} / \mathrm{MWh}$ without VAT and STANDARD included green electricity for $1729 \mathrm{CZK} / \mathrm{MWh}$ without VAT

. On the first sight we can see on the website marketing message why customer should consider green electricity. The reason is mostly supporting renewables, increasing demand for renewables which aims to decreasing of $\mathrm{CO} 2$. If we would go deeper and check the website in bigger detail, we would notice an explanations how green electricity works. In case of CEZ, the company explained the extra price -it is a special fee for issuing the certificate, so there is no further money transfer to manufacturer. They claim, that thanks to higher demand, there is a higher supply of green electricity in the network. As we mentioned before, the energy cannot be stored and market is almost non elastic, because of high primary investments and legal framework. Therefore, it is impossible to increase supply in short time, especially if certificates do not increase income of the manufacturer. The fee for certificates only causes dead weight loss because the extra money which customer pays is transferred to operator and not to power plants.

Another company, E.ON, which is the biggest purchaser of green energy in Czech Republic, explains, that there are limited renewable resources in Czech republic and that is why in the case of too high demand they would buy certificates abroad - once again, the powerplants cannot react on higher demand because of the barriers of the market. This fact eliminates the added value that customers are improving their living standards, because they are not - not in centralized network. 
The certificates are tradable within the whole European union, which decrease the effect of improving living standards - however analysed big players claim to buy green energy only from Czech companies, smaller suppliers do not guarantee this

. Despite the fact the advertisement of the product of green electricity started, the total amount of the renewables purchased in energy mix did not increase - the reason is limited demand of the customers based on customer research which is lower than offer of the suppliers presented in table 3 .

Table 3. Suppliers' energy mix in 2019

\begin{tabular}{|l|c|c|c|}
\hline & ČEZ & E.ON & PRE \\
\hline Renewables & $4,43 \%$ & $22,93 \%$ & $4,26 \%$ \\
\hline Fossil & $53,50 \%$ & $49,63 \%$ & $56,91 \%$ \\
\hline Nuclear & $42,06 \%$ & $27,44 \%$ & $38,83 \%$ \\
\hline
\end{tabular}

Source: ČEZ, E.ON, PRE

\section{Conclusion}

Conclusion following the analysis is that the trade model of Renewable Energy Guarantees of Origin has negligible impact as growth stimulator of the industry. The guarantees are more likely to be only a marketing tool which could be considered a part of the greenwashing trend - so called green solution without real impact on the environmental aspects. The real cost for the customer is death weight loss caused by transaction costs which increase final commodity price. On the other hand, the benefit is low, because of the central network and tradable certificates, where is no guarantee that customer would decrease the emission within own living area.

There are known other tools which can support renewables directly without causing dead weight loss, but they are not object of the paper.

\section{References}

1. ARENT, D., et al. (2014). Implications of high renewable electricity penetration in the US for water use, greenhouse gas emissions, land-use, and materials supply. Applied Energy, 123, 368-377.

2. GOETT, A. A., HUDSON, K., \& TRAIN, K. E. (2000). Customers' choice among retail energy suppliers: The willingness-to-pay for service attributes. The Energy Journal, 1-28.

3. KONTOGIANNI, A., TOURKOLIAS, C., \& SKOURTOS, M. (2013). Renewables portfolio, individual preferences and social values towards RES technologies. Energy Policy, 55, $467-$ 476.

4. MCGOWAN, Francis. (1990). Towards a European Electricity Market.” The World Today, vol. 46, no. 1, str. 15-19. Available from: www.jstor.org/stable/40396146. .

5. MORRISS, Andrew P. The false promise of green energy / Andrew P. Morriss ... [et al.]. 2011. ISBN 9781935308416.

6. . RUSCHE, T. M. (2015). EU renewable electricity law and policy : from national targets to a common market. Cambridge: Cambridge University Press. 290 str. ISBN 9781107533240.

7. http://www.cez.cz (access date: 5-4-2021). . 
8. http://www.eon.cz (access date: 5-4-2021)..

9. http://www.eru.cz (access date: 5-4-2021).

10. http://www.pre.cz (access date: 5-4-2021). .

11. http://www.ote-cr.cz.cz (access date: 5-4-2021)). 